\title{
O processo criativo de Fernando Pessoa: o diálogo com o positivismo
}

\author{
The creative process of Fernando Pessoa: the dialogue with positivism \\ El proceso creativo de Fernando Pessoa: el diálogo con el Positivismo
}

\section{Álvaro Cardoso Gomes ${ }^{1} 1$ \\ Manoel Francisco Guaranha $\odot^{2}$}

1 Universidade de São Paulo/Universidade de Santo Amaro, São Paulo/Santo Amaro, São Paulo, Brasil. 2Universidade de Santo Amaro/Faculdade de Tecnologia de São Paulo, Santo Amaro/São Paulo, São Paulo, Brasil.

\author{
$\diamond$
}

\section{RESUMO}

Este artigo tem como objetivo estudar o processo de criação de Fernando Pessoa (1888-1935) a partir de uma visão interdisciplinar que articula Literatura, Filosofia, História e Ciências Sociais para destacar o diálogo do poeta português com o Positivismo de Auguste Comte (1798-1857), notadamente no que diz respeito à Teoria do Conhecimento: enquanto Comte investe na unidade, o processo criativo de Pessoa aponta para a diversidade como forma de compreensão dos fenômenos. Em parte, acreditamos que isso se deve à perspectiva do tempo em que Pessoa viveu, às influências do Decadentismo do final do século XIX e aos ventos da Modernidade que redimensionaram os modos de pensar do século XX.

Palavras-chave: Literatura Portuguesa. Processo heteronímico. Auguste Comte. Teoria do Conhecimento.

\begin{abstract}
This article aims to study the process of creation of Fernando Pessoa (1888-1935) from an interdisciplinary vision that articulates Literature, Philosophy, History and Social Sciences to highlight the dialogue of the Portuguese poet with the Positivism of Auguste Comte (1798-1857), notably in respect of the Theory of Knowledge: while Comte invests in unity, Pessoa's creative process points to diversity as a way of understanding phenomena. In part, we believe that this is due to the perspective of the time in which Pessoa lived, to the influences of the Decadentism of the late nineteenth century, and to the ideas of Modernity that reshaped the twentieth-century ways of thinking.
\end{abstract}

Keywords: Portuguese Literature. Heteronymic process. Auguste Comte. Theory of Knowledge.

\section{RESUMEN}

En este artículo se pretende estudiar el proceso de creación de Fernando Pessoa (1888-1935) desde una visión interdisciplinar que articula Literatura, Filosofía, Historia y Ciencias Sociales para poner de relieve el diálogo del poeta portugués con el Positivismo de Auguste Comte (17981857), especialmente en lo que se refiere a la Teoría del Conocimiento: mientras Comte busca la unidad, el proceso creativo de Persona apunta a la diversidad como forma de comprensión de los fenómenos. En parte, creemos que esto se debe a la perspectiva del tiempo en que Fernando Pessoa vivió, a las influencias del Decadismo de finales del siglo XIX y también a los vientos de la Modernidad que redimensionaron los modos de pensar del siglo XX.

Palabras clave: Literatura Portuguesa. Proceso de los heterónimos. Auguste Comte. Teoría del Conocimiento. 


\section{Considerações iniciais}

Levando-se em conta esse contexto em que Fernando Pessoa (1888-1935) viveu e produziu, este artigo propõe-se a fazer uma leitura do processo heteronímico desenvolvido pelo poeta sob a perspectiva de um diálogo polêmico de um homem do século $\mathrm{XX}$, marcado pela modernidade, herdeiro de certa visão decadentista, com as propostas do Positivismo do século XIX, notadamente no que diz respeito à visão do método científico como panaceia universal. Para tanto, o texto será dividido em três seções nas quais: 1) traçaremos um breve quadro da perspectiva comteana sobre o desenvolvimento do pensamento humano; 2) elencaremos e discutiremos as ideias de Pessoa sobre Comte e a Ciência; e 3) apresentaremos um quadro dos três grandes heterônimos de Pessoa Alberto Caeiro, Ricardo Reis e Álvaro de Campos e dele próprio por meio de sua obra ortônima. Nesse ponto, destacaremos as diferentes perspectivas do homem em relação ao conhecimento da realidade, bem como o diálogo crítico, promovido por Pessoa, homem cindido, com a busca da unidade empreendida por Comte. A crítica pessoana ao Positivismo revela que, paradoxalmente, a busca da unidade pode conduzir à diversidade.

\section{Comte: o pensamento positivo e a universalidade do método}

Auguste Comte (1798-1857) "pode, legitimamente, ser considerado como o 'inventor' da sociologia" (BOURDÉ; MARTIN, 1990, p. 51). Preocupando-se com o estudo do "desenvolvimento total da inteligência humana em suas diversas esferas de atividade, desde seu primeiro voo mais simples até nossos dias" (COMTE, 1991, p.3), o filósofo afirma ter descoberto a lei dos três estados: "Essa lei consiste em que cada uma das nossas concepções principais, cada ramo de nossos conhecimentos, passa sucessivamente por três estados diferentes: estado teológico ou fictício, estado metafísico ou abstrato, estado científico ou positivo" (COMTE, 1991, p. 3).

Esses três estados ou métodos de filosofar que o homem aplica em suas investigações, além de serem categorizados, são explicitados por Comte no trecho a seguir:

No estado teológico, o espírito humano, dirigindo essencialmente suas investigações para a natureza íntima dos seres, as causas primeiras e finais de todos os efeitos que o tocam, numa palavra, para os conhecimentos absolutos, apresenta os fenômenos como produzidos pela ação direta e contínua de agentes sobrenaturais mais ou menos numerosos, cuja intervenção arbitrária explica todas as anomalias parentes do universo.

No estado metafísico, que no fundo nada mais é do que simples modificação geral do primeiro, os agentes sobrenaturais são substituídos por forças abstratas, verdadeiras entidades (abstrações personificadas) inerentes aos diversos seres do mundo, e concebidas como capazes de engendrar por elas próprias todos os fenômenos observados, cuja explicação consiste, então, em determinar para cada um uma entidade correspondente.

Enfim, no estado positivo, o espírito humano, reconhecendo a impossibilidade de obter noções absolutas, renuncia a procurar a origem e o destino do universo, a conhecer as causas íntimas dos fenômenos, para preocupar-se unicamente em descobrir, graças ao uso bem combinado do raciocínio e da observação, suas leis efetivas, a saber, suas relações invariáveis de sucessão e de similitude. A explicação dos fatos, reduzida então a seus termos reais, se resume de agora em diante na ligação estabelecida entre os diversos fenômenos particulares e alguns fatos gerais, cujo número o progresso da ciência tende cada vez mais a diminuir (COMTE, 1991, p.4).

Assim como o sistema teológico teria evoluído quando fez convergir as numerosas entidades divinas do politeísmo para o Deus único do monoteísmo, a metafísica também teria evoluído quando substituiu as abstrações personificadas por uma entidade geral, a natureza. Isso levou Comte a supor que o sistema positivo poderia evoluir de modo a "poder representar todos os diversos fenômenos observáveis como casos particulares dum único fato geral" (COMTE, 1991, p.4).

O desejo de Comte em encontrar a unidade perpassa seu "Curso de filosofia positiva" de tal modo que estabelece como objetivo fundamental da disciplina "tomar todos os fenômenos como sujeitos a leis naturais invariáveis, cuja descoberta e cuja redução ao menor número possível constituem objetivo de todos os esforços" (COMTE, 1991, p.7). As causas desses fenômenos seriam postas de lado pelos investigadores positivistas e a ênfase seria dada em "analisar com exatidão as circunstâncias de sua produção e vinculá-las umas às outras, mediante relações normais de sucessão e de similitude" (COMTE, 1991, p. 7).

Em contraposição ao mergulho nas origens proposto pelas perspectivas mítica e metafísica, Comte propõe o ingresso da mente no processo de desenvolvimento do fenômeno de modo a lhe desvendar as engrenagens e sua forma de articulação com outros fenômenos. Podemos dizer, nesse sentido, que Comte propõe a busca de uma unidade positivista em substituição às diversidades teológica e metafísica.

Considerada como "verdadeiro estado definitivo da inteligência humana" (COMTE, 1991, p. 6), o soció- 
logo sustenta que a filosofia positiva ainda não teria sido aplicada, no tempo dele, a todas as categorias de fenômeno. Os fenômenos astronômicos, físicos, químicos e fisiológicos já estavam sendo contemplados, mas faltava ao "espírito humano, tão disposto à unidade de método" (COMTE, 1991, p.9) aplicar esse modo de conhecer os fenômenos sociais para se criar a física social, uma vez que na visão de Comte, àquela altura, os métodos teológicos e metafísicos, já abandonados na explicação das demais categorias de fenômenos, ainda eram aplicados os estudos sociais.

A fundação da física social completaria, assim, o sistema das ciências naturais e todas as concepções fundamentais seriam homogeneizadas e poderiam desenvolver-se indefinidamente com o acréscimo de novos conhecimentos obtidos por meio dos processos de observação e experimentação que dariam à filosofia positiva o caráter de universalidade.

Em que pesem as contribuições de Comte ao pensamento moderno, as circunstâncias históricas contemporâneas a ele revelam certo idealismo do positivista que, se por um lado parece buscar os universais aristotélicos, por outro aponta-nos para um tipo de Platonismo revisitado, à luz do mundo real é bem verdade, mas no fundo tão idealista quanto aquele Platonismo original para o qual a Verdade convergia para o caráter unitário do mundo das ideias com seus arquétipos únicos e primeiros.

Concebido como espécie de panaceia, o Positivismo acabou desaguando em uma nova religião da humanidade. Nos últimos quinze anos de sua vida, Comte não só estabeleceu os princípios fundamentais dessa nova religião, que substituía o Deus cristão pela Humanidade, como publicou $O$ Catecismo Positivista ou Exposição Sumária da Religião Universal, em 1852.

\section{Fernando Pessoa: a visão crítica do Positivismo}

O século XIX foi marcado, em grande parte, pelo desenvolvimento tecnológico propiciado pelo método científico. Observação e experimentação como bases de uma investigação que punha em segundo plano os dogmas religiosos compuseram a perspectiva positivista que se apresentou como capaz de compreender os mecanismos da natureza e colocá-los a serviço do homem. Máquinas potentes para percorrer longas distâncias, comunicação mais abrangente, remédios e vacinas, informação diária disponível entre outros benefícios foram os resultados concretos obtidos pela Ciência que pareciam ser capazes de levar o homem à solução de todos os seus problemas.

Pouco durou, contudo, a lua de mel entre o homem do Ocidente e a Ciência. Mesmo em países menos industrializados como Portugal e sob a perspectiva de um antes convicto realista, Eça de Queirós (1845-1900), cujo estilo fora afinado, em grande parte, com o ideário do Positivismo, encontramos um Jacinto intoxicado de progresso material no conto "Civilização", publicado originalmente em 1880. Esse personagem vai buscar na natureza um antídoto para o seu mal-estar ao procurar um modo de viver que, se não abandona completamente a técnica, encontra um meio de reduzi-la ao mínimo. Essa perspectiva é expressa pelas palavras do próprio Jacinto no momento em que já está instalado em sua propriedade rural em Torges: "É no máximo da civilização que ele [o homem] experimenta o máximo de tédio. A sapiência, portanto, está em recuar até esse honesto mínimo de civilização, que consiste em ter um teto de colmo, uma leira de terra e o grão para nela semear" (QUEIRÓS, [198-?], p. 54).

A visão decadentista do século XIX é desenhada na descrição final desse mesmo conto quando o narrador, amigo de Jacinto, visita a antiga mansão do protagonista para buscar uns livros solicitados pelo amigo:

[...] penetrei no gabinete de trabalho de Jacinto e tropecei num montão negro de ferragens, rodas, lâminas, campainhas, parafusos... Entreabri a janela, e reconheci o telefone, o teatrofone, o fonógrafo, outros aparelhos, tombados das suas peanhas, sórdidos, desfeitos sob a poeira dos anos. Empurrei com o pé este lixo do engenho humano. A máquina de escrever, escancarada, com os buracos negros marcando as letras desarraigadas era como uma boca alvar e desdentada. O telefone parecia esborrachado, enrodilhado nas suas tripas de arame.

$\mathrm{Na}$ trompa do fonógrafo, torta, esbeiçada, para sempre muda, fervilhavam carochas. E ali jaziam, tão lamentáveis e grotescas, aquelas geniais invenções, que eu saí rindo, como de uma enorme facécia, daquele supercivilizado palácio.

A chuva de Abril secara: os telhados remotos da cidade negrejavam sobre um poente de carmesim e ouro. E, através das ruas mais frescas, eu ia pensando que este nosso magnífico século XIX se assemelharia um dia àquele Jasmineiro abandonado, e que os outros homens, com uma certeza mais pura do que é a Vida e a Felicidade, dariam como eu com o pé no lixo da supercivilização, e, como eu, ririam alegremente da grande ilusão que findara, inútil e coberta de ferrugem (QUEIRÓS, [198-?], p. 54-55).

Essa visão de uma civilização em crise, que já era perceptível no clima do Realismo, ganha força no Decadentismo, um dos movimentos precursores das Vanguardas Europeias do século XX. Segundo Teles(1987), o Manifesto Decadente de Anatole Baju, publicado em 1886, retomava a visão de uma "civilização deliquescente" (TELES, 1987, p.57) que não era nova, 
antes expressão de uma "tendência antiga nas literaturas [...] um fluxo e refluxo dinamizador da história cultural e se explica talvez por essa dialética entre o real e o irreal que assinala a trajetória do homem e, portanto, os movimentos literários" (TELES, 1987, p. 55).

Fernando Pessoa não viveu exatamente clima do século XIX, nem comungou da inocência de um Jacinto da primeira fase, encantado com o com a civilização positivista e cientificista, mas sentiu os reflexos da "dialética entre o real e o irreal", do desencanto do homem com a Ciência, fenômenos que se projetaram ao longo da primeira metade do século XX e foram materializados literariamente nas Vanguardas Europeias:

... nomes como os de Laforgue, Moréas e Rodenbach e obras como $A$ rebours (1884), de Huysmans, e $O$ retrato de Dorian Gray (1891), de Oscar Wilde, marcaram o ponto alto da ficção de decadentista. Diga-se, de passagem, que o "Prefácio" de Wilde é um verdadeiro manifesto, terminando com a afirmação de que 'Toda arte é absolutamente inútil', tal como, em 1917, vai também proclamar o fundador do dadaísmo (TELES, 1987, p. 56).

Nesse contexto, Fernando Pessoa estabeleceu um diálogo direto com Comte em alguns momentos de seus escritos. Em Páginas íntimas e de autointerpretação, por exemplo, apontou o paradoxo da religião universal comteana:

Comte teve uma justa intuição quando viu que ciência positiva, de per si, não bastava para orientar a sociedade, e quis, portanto, tornar essa ciência uma religião. Filho, porém, do seu tempo e oriundo, sem que o soubesse, do próprio ventre maculado contra o qual se revoltou, que fez ele, que quis ele fazer? Construir para forma vital da ciência, uma religião da humanidade, patente descendente da religião humanitária da Revolução Francesa. Mémores de tanta coisa que não viu mal, relevemos ao pobre alienado os desvios que herdou da sua época. [...]

A religião - sabe-o já o leitor deste livro - é dos sentidos e da emoção directa e geral. E o paganismo que é a religião da época da ciência. A ciência é filha do paganismo, porque a ciência é grega - a nossa pelo menos. Estranho caso o de um homem que procura com afinco encontrar uma coisa que já existe! (PESSOA, 1996, p. 270).

Em outro momento, Pessoa questionou o "preconceito comtista da Ordem". Estabelecendo uma analogia entre a ordem das sociedades e a saúde do indivíduo, afirma que o homem normal, frente à doença, não procuraria afastar os sintomas, mas a doença em si. Nesse sentido, não bastaria para um homem estar sem os efeitos da doença momentaneamente para se achar curado, mas saber que a causa foi debelada. De modo semelhante, "Na sociedade [...]: quando aparece a desordem, a sociedade sã procura logo não manter a ordem, que pode ser provisória ou aparente, mas atacar o mal que produziu a desordem. A exclusiva preocupação da ordem é um morfinismo social" (PESSOA, 1979, p. 89). Da mesma forma "Na sociedade, paralelamente, a preocupação da ordem é uma doença de espírito colectivo" (PESSOA, 1979, p. 89), doença essa, segundo Pessoa, surgida do cérebro do "infeliz Auguste Comte, [que] toda a vida sofreu de alienação mental" (PESSOA, 1979, p. 89).

Quando definiu Ciência, o poeta afirmou que essa forma de conhecimento trata do:

modo de actividade (intelectual) humana que investiga as leis - isto é, as relações constantes - das coisas. Não há ciência senão das relações entre as coisas; porque de uma coisa isolada não pode haver ciência, nada se concluindo da existência de uma coisa isolada senão o mero facto de que essa coisa existe. Mesmo a investigação da natureza de uma coisa qualquer não é senão a investigação d'aquilo em que essa coisa difere de, ou se parece com, outras coisas (PESSOA, 1993, p. 255).

Ainda que fale em leis e em relações constantes, a perspectiva pessoana sobre ciência abre uma fenda no sonho reducionista da busca da universalidade de Comte. Para o escritor português, sujeito e objeto serão sempre como água e azeite haja vista que

A base de toda a especulação é a distinção entre Sujeito e Objecto. (À relação entre eles chama-se Conhecimento). (Na emoção e na vontade não há $\mathrm{S}$ [ujeito] e O[bjecto] mas só dois objectos). [...] $\mathrm{S}$ [ujeito] e O[bjecto] são irredutíveis. Nada que é Objecto pode ser Sujeito, nada que é Sujeito pode ser Objecto [...] Duas coisas ficam: a Consciência e a Realidade (PESSOA, 1968, p. 194).

Pressupõe-se pela fala de Pessoa que emoção e vontade seriam formas de o sujeito perder-se enquanto sujeito e tornar-se mais um objeto entre os objetos da natureza. Talvez seja por isso que no poema "Autopsicografia" (PESSOA, 1995, p. 235) ele afirmou, na última estrofe que dedicou à grafia, ao objeto literário, portanto, que o comboio de corda que se chama coração gira nas calhas de roda, nos trilhos da razão, a entretê-la. Ao mesmo tempo que entretém, distrai a razão: o coração depende desta para se movimentar já que não o faria no solo puro não pavimentado pela estrutura racional, por assim dizer, do trilho de ferro.

Essa dicotomia entre o ser e as coisas não permite que o homem chegue a um elemento essencial, unitário, antes é ponto de partida para a construção da diversidade, posto 
que as próprias relações entre as coisas são "de três ordens conforme resultem da mera comparação das coisas umas às outras, das influências de umas sobre outras, ou da origem de uma com respeito às outras" (PESSOA, 1993, p. 255).

Para Pessoa, não se pode afirmar que a Consciência exista, porque isso seria afirmar que ela é Objeto, "e ela é, essencialmente, o Sujeito Puro" (PESSOA, 1968, p. 194). Além disso, o poeta-filósofo categoriza a realidade em três níveis: concreta, a que é sentida como objeto; imediata ou reflexa, a que é sentida como sujeito; e abstrata, "a que é sentida como nem uma coisa". Para esta terceira categoria, Pessoa apresenta as seguintes características: "(1) o indefinido, que se torna o infinito quando abusivamente tido por concreto; (2) o todo, porque cada ideia abstracta abrange um todo dos conjuntos concretos; (3) a perfeição, porque muito falta no que nada é" (PESSOA, 1968, p. 194).

Essas formas de conhecimento fundem-se constantemente na experiência humana e o ser está sujeito ao erro quando atribui características de uma à outra. Pessoa enumera sete desses erros a saber: quando se toma o sujeito por objeto; quando se toma o abstrato por concreto, que equivaleria ao Idealismo; quando se toma o concreto por abstrato, que equivaleria ao Materialismo; quando se toma o relativo por concreto, que equivaleria a acreditar que as coisas são as relações que elas mantêm com outras; quando se toma o concreto pelo relativo; quando se toma o relativo por abstrato, aqui Pessoa toma o exemplo de Heráclito e seguidores, que diziam que tudo era movimento; e quando toma o abstrato por relativo, erro que exemplifica pelo conceito de Ser-Natureza (PESSOA, 1968, p. 194).

Essa gama enorme de possibilidades de erros decorrentes da experiência, aquela mesma que alicerça o método positivista (emparelhada à observação que não deixa de ser uma forma de experimentação), faz com que Pessoa seja refratário à certeza no caráter objetivo da percepção e "na conformidade das nossas ideias com a 'realidade' ou a 'verdade"'. Ele considera a certeza "um sintoma de ignorância ou de loucura". Vale dizer que "O homem mentalmente são não está certo de nada, [...] vive numa [...] instabilidade mental permanente; e, como a instabilidade mental permanente é um sintoma mórbido, o homem são é um homem doente" (PESSOA, 1968, p. 246).

Vista da perspectiva da diversidade, a concepção de Pessoa diverge da de Comte, haja vista que o positivista buscava a unidade ao dizer que o espírito positivo, ao liberar-se dos regimes teológicos ou metafísicos torna

homogêneas todas as nossas concepções reais, [e com isso] a unidade especulativa tende logo a estabelecerse espontaneamente de modo a fornecer uma sólida base objetiva para a sistematização total, que constitui a finalidade característica da verdadeira filosofia (COMTE, 1991, p. 60).
Neste ponto, a crítica de Pessoa à suposta independência da Ciência em relação às outras formas de conhecimento deságua na ideia de que aquela funde-se à religião na intuição determinista, a de criar a Religião da Humanidade:

É, porém, um facto curioso que a religião e a ciência têm a mesma base - a intuição determinista. A noção de lei é fundamental na ciência, e na mentalidade científica; sem que haja uma noção de lei, nem pode haver ciência, nem quem busque fazer ciência.

Mas esta mesma noção do determinismo é que é o fundamento da religião; porque a religião não passa na essência, do reconhecimento de que a vida, a acção, tudo quanto somos e representamos, não tem origem ou explicação em nós mesmos, mas está nas mãos de um poder ou poderes desconhecidos (PESSOA, 1968, p. 92).

Baseados nessa postura crítica de Pessoa em relação a Comte, traçaremos um quadro crítico dos heterônimos pessoanos, que inclui também considerações sobre a obra ortônima do poeta. A vasta obra, tanto a heterônima quanto a ortônima, materializa poeticamente esse possível diálogo entre as perspectivas filosóficas comteanas e a consciência da diversidade em Fernando Pessoa.

\section{Fernando Pessoa(s): a unidade na diversidade}

Fernando Pessoa, em Páginas Íntimas e de AutoInterpretação (1966), por meio de seu heterônimo António Mora, esboça uma interpretação do surgimento dos deuses. Curiosamente, acaba por esboçar também uma interpretação dos heterônimos. Mora faz uma síntese cultural da história da humanidade:

$\mathrm{Na}$ evolução do espírito humano de pensamento concreto para o pensamento abstrato, há fatalmente um momento em que se dá a transição de uma forma de conceitos para a outra. (...) A evolução humana tem sido uma ascensão da capacidade de ter só ideias concretas para a capacidade de ter ideias abstratas (PESSOA, 1966, p. 304-305).

Em síntese, é possível apontar três frases nessa evolução: primeiramente, a pré-história, quando o homem mantém relação concreta com o real. Em segundo lugar, o momento em que a abstração começa a interferir na relação entre o homem e as coisas, provocando o surgimento dos deuses. Os deuses, em parte, explicariam os fenômenos como a chuva, o fogo, o vento etc. Por outro lado, representariam concretamente os valores ideais abstratos. Finalmente, o instante em que a abstração instaura-se de vez. Nesse momento, a Ciência explica os 
fenômenos e os deuses cedem lugar a uma só Deus, não mais concebido à semelhança do homem, mas possuidor das qualidades e defeitos humanos.

Os heterônimos, portanto, seriam consciências que se identificariam com as três fases insinuadas por Pessoa, cada uma delas concebendo o mundo de uma perspectiva. O poeta, por meio dessas figuras-chave, procuraria abranger a história da Humanidade, ao invés de tentar explicar o Universo do ponto de vista isolado de um "eu". Essa multiplicação de Pessoa implicaria o conhecer amplo, total, da realidade, numa síntese perfeita. Como se ele tentasse recuperar a figura do homem do homem cósmico da Renascença, cujas medidas do corpo correspondessem, em escala menor, às do universo. E dentro dessa concepção cósmica, história da humanidade feita de metáforas, não é difícil situar Alberto Caeiro na primeira época sugerida pelo poeta. "O guardador de rebanhos" vive em um tempo anterior ao surgimento do logos (ou pelo menos, finge que vive). É o eterno ato de criar, que se instaura diante de nós. Mundo tão inocente, que o poeta recupera, que dispensa os deuses. Os fenômenos não se explicam - as coisas são as coisas em sua virginal inocência. Não há como lhes explicar o modo de ser. O olhar que as capta é o olhar límpido "como um girassol", que registra as coisas no instante magnífico e único de seu surgir. In praesentia. Daí vem que, longe delas, essa consciência, ávida pelo concreto, não as apreenda. Caeiro é o poeta da evidência que busca a "coisidade" das coisas, o seu estar aí, anterior à mistificação imagística e/ou metafisica". Em busca do grau zero do ser das coisas e homem-criança percorre, com seu cajado, o caminho inverso da a inocência perdida.

É por isso que Caeiro geralmente é aceito como verdadeira matriz das figuras concebidas por Pessoa: sua poesia situa-nos no instante mágico da deflagração do processo civilizatório. Mais ainda: Caeiro é entendido como o mestre de todos os heterônimos. Isto se deve aos ensinamentos que veicula por meio do aprendizado de desaprender. Seu método implica retirar os disfarces com que se camufla a realidade para chegar até as coisas, vistas em sua plenitude de coisas, diante do olhar do primeiro homem que busca nomeá-las. $\mathrm{Na}$ realidade, a lição do mestre Caeiro pauta-se por um ato de nomeação ao invés de aceitar o real por meio da projeção mental do homem que em sua evolução deformou-o: procura ver o real sem pensá-lo. É preciso considerar também que Caeiro ensina aos outros como como enfrentar a ruptura entre o ser e o mundo, ruptura esta causada pela reflexão. Situado nessa ficção, que é o espaço edênico da integração plena entre o homem e as coisas, pré-história, época do "pensamento concreto".

No prefácio que Ricardo Reis escreve para Alberto Caeiro, há uma reflexão sobre a invenção dos deuses:
Para Caeiro, objetivista absoluto, os próprios deuses pagãos eram uma deformação do paganismo. Objetivista abstrato, os deuses já eram a mais no seu objetivismo. Ele bem via que eles eram feitos à imagem e semelhança das cousas materiais mas não eram as cousas materiais, e isso lhe bastava para que nada fossem" (PESSOA, 1966, p. 399).

Ricardo Reis pensa desse modo, porque já se situa no segundo momento cultural da humanidade, de acordo com os apontamentos de António Mora. É o momento em que se dá a transição de uma forma de conceitos forma para a outra", ou seja, a transição de que fala o heterônimo é a da passagem do "pensamento concreto" para o "pensamento abstrato". Como, porém, nesse estágio, a abstração ainda não tem autonomia, ela se apoia em determinadas figurações. Assim, o fenômeno da chuva é personificado numa figura, num deus, o fenômeno do vento num outro deus, Éolo, por exemplo. De acordo com o próprio Ricardo Reis,

[...] os deuses gregos representam a fixação abstrata do objetivismo concretizador. [...] Os deuses pertencem à categoria das abstrações, no que respeita à sua relação com a realidade, mas não pertencem a essa categoria como abstrações, porque o não são. Como as ideias abstratas nos servem para nos conduzirmos entre as cousas, os deuses servem-nos também para nos conduzirmos entre homens (PESSOA, 1966, p. 399).

Ora, situado em um instante em que o homem explica o mundo pela invenção dos deuses, é lógico que Reis não possua o olhar inocente de Caeiro, ainda que se pretenda materialista e objetivista como o mestre. Quem fala aqui é o aristocrático e refinado homem que se senta à margem do rio, ao lado de Lídia, contemplando o espetáculo sempre mutável das coisas, com aquela atitude impassível de quem sabe inútil qualquer resistência ao Fado. Sim, porque Ricardo Reis já pensa o mundo - a razão de tudo, explicação mais que plausível do Universo, repousa nos deuses, ou melhor, em algo acima deles, o sempre inescrutável Fado. Se Alberto Caeiro se recusava a pensar sequer na razão primeira dos fenômenos ("sei lá o que penso das coisas"), este "pagão da decadência", pelo menos, sabe que tudo emana de uma, potência cega e superior a ele. Contudo, não lhe cabe - aliás, sabiamente questionar e/ou pensar o porquê de as coisas serem como são, ou de terem o destino que têm. Se, ainda, Alberto Caeiro não pensa (ou pelos menos diz que não pensa), Ricardo Reis, conscientemente, envereda pelo labirinto da consciência para pensar o mundo e o homem, com vistas a encontrar um equilíbrio ideal entre ambos. Embora saiba que a Ciência humana é falha, não deixa de utilizá-la para encontrar seu lugar na Natureza. A diferença, portanto, entre Caeiro e Reis reside no fato de que, embora ambos 
pensem, aquele o faz visando retornar à aurora o mundo, enquanto este, pelo contrário, se apoia num sistema de pensamento preexistente, para enfrentar os dilemas da morte e do destino.

Quando se instaura de vez a mediação abstrata entre o homem o mundo, nascem o Pessoa ortônimo e Álvaro de Campos, manifestando dois modos distintos de representar a cisão provocada pelo logos. O primeiro fecha-se em seu mundo e explora, de modo labiríntico o desespero surdo, expresso por meio de uma falha miniloquente. A emoção surge controlada pela consciência, que evita o extravasamento sentimental, pela musicalidade do verso ou pela sistemática montagem de um espaço onírico, em que a palavra se dilui num modo de falar essencialmente sugestivo. Ao mesmo tempo, que ancora numa voz tradicional portuguesa, Pessoa explora o princípio de uma solidão cósmica, o sentir-se como o "emissário de um rei desconhecido". O Fernando Pessoa ortônimo vai problematizar, portanto, o seu ensimesmamento em face de uma realidade que não lhe suporta os sonhos.

Ao lado da solidão, o poeta de o Cancioneiro também poetiza a cisão entre ele e o mundo, causada pelo excessivo pensar. "O que em mim sente "stá pensando" (sic), diz Fernando Pessoa ao ouvir "a incerta voz ondeando", de uma ceifeira (PESSOA, 1995, p. 108). $\mathrm{O}$ canto da mulher se lhe oferece como um símbolo de algo puro, não contaminado pela inteligência e que serve de contraponto à ânsia, provocada pela interferência do racionalismo: "A ciência/Pesa tanto e a vida é tão breve" (PESSOA, 1995, p. 108). Desse modo, explica-se por que a poesia do ortônimo é tão impregnada de musicalidade: por ser a música a mais subjetiva das artes, ela tem um alto poder sugestivo. Ora, a poesia concebida como música tem o poder de rarefazer o significado a tal ponto que, de modo ilusório, atenua no poeta a força da reflexão, paradoxalmente, o meio de que ele se serve para contatar o real.

Álvaro de Campos, por seu turno, embora manifeste também a ruptura entre o ser e o mundo, como o resultado da aguda reflexão sobre o real, apresenta tal problemática de maneira diferente de Pessoa. Álvaro de Campos é o poeta da revolta, do desespero suicida. Profeta do mundo moderno, deixa que lhe invadam as odes o ruído das máquinas, como que fazendo do poema um núcleo para o qual convergem forças de várias direções. Se Pessoa preza os metros tradicionais, a "naturalidade" das canções populares, se valoriza a harmonia somente rompida pela existência de um "eu" dilacerado, Álvaro de Campos já projeta tal consciência ostensivamente na forma, criando uma "melodia" dissonante. A poesia é tomada pelo "lixo" do mundo ocidental: tipos anômalos, como o senhor respeitável que se deixa masturbar por crianças nos vãos das escadas, cocotes, pederastas, burguesinhas entre outros.
Assim, parece que, em Álvaro de Campos, a modernidade oferece-se de maneira mais ostensiva, não só pela presença massiva dos objetos emblemáticos da civilização contemporânea, mas também pela manifestação de aguda crise de valores. Nele, a eclosão do "pensamento abstrato" como elemento mediador entre o homem o mundo provoca o estilhaçamento do "eu" a um grau ainda não visto, seja em Reis, seja em Pessoa. Tudo isso porque a sua consciência detecta o real e pensa-o, o que provoca a fragmentação tanto dele, quanto do mundo que o cerca. Mas esse processo intensifica-se ainda mais no instante em que o "eu" busca apreender os múltiplos aspectos do real, numa ânsia de conquistar a totalidade, o que evidentemente provoca a perda da unidade. $\mathrm{O}$ "o que em mim sente "stá pensando", de Fernando Pessoa, traduz-se em "sentir tudo de todas as maneiras" e penso ser tanta coisa", de Álvaro de Campos.

A esta altura, outra reflexão se impõe: este multiplicar-se, que se processa no indivíduo Fernando Pessoa e, depois, labirinticamente, em cada heterônimo, cada vez, de maneira mais ostensiva, não leva à perda da identidade? A questão já aventada, no exame de cada heterônimo, apresenta, ao lado da explicação esboçada ao longo destas páginas, que diz respeito a uma história da cultura, sobre a qual o poeta reflete para sentir o Universo como um todo, complementa-se aqui com a ideia de que o multiplicar-se e a consequente perda da unidade como que são um reflexo de uma crise de valores. Em Pessoa, verificamos "a despersonalização da lírica moderna, pelo menos no sentido que a palavra lírica já não nasce da unidade de poesia e pessoa empírica, como haviam pretendido os românticos" (FRIEDRICH, 1978, p. 36-37).

Pode ser também que Fernando Pessoa expresse, de modo agudo, a crise do "eu", ou dessa entidade chamada indivíduo, cujas raízes se encontram no nascimento do mundo moderno. Já Hume duvidara da existência do sujeito: para o autor do Tratado da Natureza Humana, aquilo que chamamos de indivíduo não passa de soma aleatória de percepções:

Eu me aventuro a afirmar, a respeito da humanidade restante, que ela não é nada mais do que um conjunto ou coleção de diferentes percepções, que se sucedem umas às outras em inconcebível rapidez, e estão num perpétuo fluxo e movimento. Assim concebido, o ser humano padece de uma desestruturação crônica, pois, de um lado, é apenas uma "coleção de diferentes percepções que se sucedem umas às outras em inconcebível rapidez, e estão num perpétuo fluxo e movimento (HUME, 1968, p. 239).

Assim concebido, o ser humano padece de uma desestruturação crônica, pois deu um lado, é apenas 
uma "coleção de diferentes percepções", de outro, a sua pressuposta unidade não passa de ficção:

Quando impropriamente atribuímos identidade a variáveis e interruptos objetos, nosso erro não se confina à expressão, mas é comumente acompanhado de uma ficção, seja de algo invariável e ininterrupto, seja de algo misterioso e inexplicável ou pelo menos com uma propensão para tais ficções (HUME, 1968, p. 241).

Na concepção de Hume, somente o hábito é capaz de conceder precária unidade aos "variáveis e interruptos objetos", que compõem nossa interioridade. Em Pessoa, ao lado da multiplicação do "eu", encontramos alguns momentos em que o poeta procura a identidade de diferentes maneiras, seja pela aniquilação da consciência, no discurso musical, seja pela ataraxia, de influência epicurista, seja pela pretensa objetividade, seja ainda pela memória, que busca unir todos os fragmentos do ser por meio de um núcleo aglutinador, que é um espaço sagrado, lar ou cidade natal, as tais contas-entes ligadas por um fio-memória, quando Álvaro de Campos revisita Lisboa:

Outra vez te revejo,

Cidade da minha infância pavorosamente perdida...

Cidade triste e alegre, outra vez sonho aqui...

$\mathrm{Eu}$ ? Mas sou eu o mesmo que aqui vivi, e aqui voltei,

E aqui tornei a voltar, e a voltar,

E aqui de novo tornei a voltar?

Ou somos todos os Eu que estive aqui ou estiveram,

Uma série de contas-entes ligadas por um fio-memória,

Uma série de sonhos de mim de alguém de fora de mim? (PESSOA, 1993, p. 249).

Contudo, tais esforços mais ainda intensificam a sensação de crise, porque sempre intervém nestes processos a consciência analítica, que impede a completa entrega do poeta ao gozo do instante, das sensações, o retorno ao espaço mágico da inocência.

\section{Considerações finais}

Fernando Pessoa expressou, nesse movimento contínuo entre a heteronímia e a ortonímia, paradoxalmente, a multiplicação e a busca da identidade perdida. Em suas páginas lemos a crise do homem contemporâneo, que se divide para tentar abarcar o universo e que, por isso mesmo, sacrifica a identidade. $\mathrm{O}$ poeta veste a máscara (ou as máscaras) e acaba se identificando com ela(s) a ponto de conscientizar-se de que está fadado a representar sempre. Atrás da máscara há sempre outra máscara. O "ter dentro de si todos os sonhos do mundo" implica o "não ser nada", o fantasma de alguém, ninguém.

Este artigo não pretende buscar uma chave para a leitura do processo heteronímico pessoano, mesmo porque isso seria negar justamente a tese de que a obra do poeta português tem como perspectiva a diversidade. Também não queremos sugerir aqui que especificamente as ideias de Comte tenham motivado uma resposta de Pessoa em forma de projeto literário. O que não se pode negar, contudo, é a preocupação do modernista lusitano em criticar a visão em certo sentido reducionista do Positivismo cujos conceitos de Ordem e de Progresso sugerem que só da regularidade linear objetiva é que se pode extrair o conhecimento.

Contrariamente, em Pessoa, as idas e vindas, o choque entre fragmentos de tempos e espaços distintos, o caos da consciência em que naufragam as certezas é que elaboram e reelaboram novos modos de se conceber a realidade. Em nossa sociedade contemporânea, dominada pela técnica, mas sensível à relatividade, é comum nos questionarmos se as leis da física são mesmo universalmente aplicáveis ou sequer se há apenas um universo. No tempo em que viveu Pessoa, porém, esse questionamento era privilégio de poucos pensadores que, se não estavam à frente de seu tempo, possuíam uma visão bem mais ampla do momento em que viviam.

\section{Referências}

BOURDÉ, Guy; MARTIN, Hervé. As escolas históricas. Mira-Sintra: Europa-América, 1990.

COMTE, Auguste. Curso de Filosofia Positiva; Discurso preliminar sobre o conjunto do Positivismo; Catecismo positivista. São Paulo: Nova Cultural, 1991.

FRIEDRICH, Hugo. Estrutura da lírica moderna. São Paulo: Duas Cidades, 1978.

HUME, David. A Treatise of human nature. Londres: J. M. Dent \& Sons, 1968.

PESSOA, Fernando. Páginas Íntimas e de Autointerpretação. Fernando Pessoa. Lisboa: Ática, 1966.

PESSOA, Fernando. Textos Filosóficos. Vol. II. Lisboa: Ática, 1968

PESSOA, Fernando. Da República (1910-1935). Lisboa: Ática, 1979.

PESSOA, Fernando. Pessoa Inédito. Lisboa: Livros Horizonte, 1993.

PESSOA, Fernando. Poesias de Álvaro de Campos. Lisboa: Ática, 1993. 
PESSOA, Fernando. Poesias. Lisboa: Ática, 1995.

QUEIRÓS, Eça. Contos. Rio de Janeiro: Ediouro/Tecnoprint. [198-?].

TELES, Gilberto Mendonça. Vanguarda europeia e Modernismo brasileiro. Rio de Janeiro: Record, 1987.

Recebido em: 09/10/2018

Aprovado em: 01/04/2019.

Publicado em: 21/06/2019.

\author{
Autores: \\ Álvaro Cardoso Gomes \\ Doutor em Letras, Literatura Portuguesa, pela USP/SP; Livre-docente \\ pela USP/SP; Pós-doutor em Portugal e nos Estados Unidos. \\ Professor Titular da USP/SP e docente do Programa em Ciências \\ Humanas (nível: Mestrado) da Universidade Santo Amaro (UNISA). \\ https://orcid.org/0000-0001-9546-1683 \\ E-mail: acgomes@prof.unisa.br \\ Endereço: Universidade de São Paulo \\ Rua do Lago, 717 - Butantã \\ 05508-090, São Paulo, SP, Brasil \\ Manoel Francisco Guaranha \\ Doutor em Letras, Literatura Portuguesa, pela USP/SP \\ Professor concursado da Faculdade de Tecnologia de São Paulo (FATEC) \\ e docente do Programa em Ciências Humanas (nível: Mestrado) da \\ Universidade Santo Amaro (UNISA). \\ https://orcid.org/0000-0002-8676-601X \\ E-mail:m-guaranha@uol.com.br \\ Endereços: Faculdade de Tecnologia de São Paulo \\ Pç. Coronel Fernando Prestes, 30 \\ Av. Tiradentes, 615 - Bom Retiro \\ 01124-060, São Paulo, SP, Brasil \\ Universidade de Santo Amaro \\ Reitoria - Pró-Reitoria de Pós-Graduação e Pesquisa \\ Rua Isabel Schmidt, 349 - Santo Amaro \\ 04743030, São Paulo, SP, Brasil
}

